\title{
Photoperiod, Temperature, and Genotype Interaction Effects on Days and Nodes Required for Flowering of Bean
}

\author{
D.H. Wallace \\ Department of Plant Breeding and Biometry, Cornell University, Ithaca, NY 14853-1902 \\ Paul A. Gniffke \\ Universal Foods, Greenfield, California \\ P.N. Masaya \\ Instituto de Ciencia y Technologia Agricolas, Guatemala City, Guatemala \\ R.W. Zobel \\ U.S. Department of Agriculture, Agricultural Research Service, Ithaca, NY 14853-1902 \\ Additional index words. plant development, cultivar adaptation, yield physiology, pleiotropic gene action, daylength, \\ Phaseolus vulgaris
}

\begin{abstract}
Number of days to flower (DTF) of 78 bean (Phaseolus vulgaris L.) genotypes was measured in tropical fields at various elevations. The associated 18 mean temperatures varied between 12 and 28C. Daylength was natural 12 or 13 hours of sunlight with or without incandescent light for a total of 18 hours. A statistical analysis with additive main effects and multiplicative interaction effects (AMMI) quantified the effects on the deviation from the DTF grand mean caused by each genotype, plus those caused by each daylength and by each temperature. The more photoperiodsensitive the genotype (factor 1), the more a longer daylength (factor 2) increased DTF and the more a higher temperature (factor 3) synergistically increased DTF. These three factors interacted to delay the node to flower. An additional control over DTF occurred as the same higher temperature (factor 3) reduced the days required to develop a node (factor 4). Thus, a higher temperature tended to decrease DTF by enhancing the rate of vegetative development, at the same time that it tended to increase DTF by enhancing the photoperiod gene activity. This four-factor interaction resulted in a U-shaped curve of DTF in response to temperature. The smallest DTF on the U-shaped response was interpreted as occurring when the simultaneous effects of temperature toward earlier and later DTF exactly cancelled. At all temperatures below this optimum for flowering, a change of temperature changed DTF predominantly by altering the days required to develop a node. At all temperatures above the optimum, a change of temperature changed DTF predominantly by altering the photoperiod-gene-caused delay of the node to flower. The optimum temperature for flowering was lowered by higher sensitivity of the genotype to photoperiod and also by longer daylength.
\end{abstract}

Most crop cultivars express a quantitative delay of DTF in response to a less promotive photoperiod (Bernier et al., 1981; Vince-Prue, 1975; Vince-Prue et al., 1984). This relationship contrasts with flowering vs. never flowering of genotypes with very high sensitivity to photoperiod. The latter, a qualitative response, is preferred for studying molecular bases of photoperiodism because it results in uniform plant development by all plants. With quantitative response, variability among plants in the rate of development to flowering increases as the photoperiod gene activity delays the flowering (Dormling et al., 1975; D.H.W., unpublished data).

The quantitative delay of DTF is partially controlled by qualitative variations of one to a few photoperiod gene(s), including their multiple alleles (Murfet, 1977; Wallace, 1985). Genotypes are classified as photoperiod-insensitive, moderately, or highly sensitive, as the quantitative delay of DTF that they cause is enlarged in response to the same nonpromotive daylength. Thus, the quantitative delay depends on both the qualitative variation of the genotype (control 1 over DTF) and the daylength (control

\footnotetext{
Received for publication 27 June 1990. Dept. of Plant Breeding Paper no. 783. This research was supported by Hatch funds and the Bean/Cowpea Collaborative Research Program funded by USAID. The research also used fields, facilities, and resources of the Centro International de Agricultural Tropical (CIAT), Cali, Colombia, and of the Instituto de Ciencia y Tecnologia Agricolas, Guatemala City, Guatemala. The cost of publishing this paper was defrayed in part by the payment of page charges. Under postal regulations, this paper therefore must be hereby marked advertisement solely to indicate this fact.
}

2). The daylength varies quantitatively across calendar time. The quantitative delay of DTF by photoperiod gene activity depends additionally on quantitative variations of the mean temperature (control 3) (Murfet, 1977; Wallace and Enriquez, 1980). Interactively, a genotype with greater sensitivity to photoperiod, a more nonpromotive daylength, and a higher temperature will enlarge the number of nodes that develop before the first flower (the node to flower) and thereby strongly control the expressed DTF (Bemier et al., 1981; Kinet et al., 1985; Vince-Prue, 1975).

Additional interactive control over DTF occurs as the temperature simultaneously alters the rate of vegetative development (control 4). It has been shown for many crops that a higher temperature causes the nodes to develop in fewer days (Aitken, 1974, 1980; Berry and Aitken, 1979; Craufurd and Bidinger, 1988; Lamoreaux et al., 1978; Tollenaar and Hunter, 1983). Temperature control over this rate of vegetative development usually has been studied with young plants, mostly without reference to the photoperiod-gene $\times$ daylength $\times$ temperature control over the node to flower. We will show that the alteraions by temperature of the rate of vegetative development and the alterations by both daylength and temperature of the rate of reproductive development interact to jointly control the rate of

Abbreviations: AMMI, additive main effects and multiplicative interaction effects; DTF, days to flower; $\mathrm{G} \times \mathrm{E}$, genotype $\times$ environment; IPCA, interaction principal component analysis; NTF, node to first flower; PCA, principal component analysis. 
development to flowering. Interactions among the above four factors only partially control DTF because DTF is additionally altered by genes that determine the number of nodes (control 5) (Evans, 1973; D. H.W., unpublished data). DTF is also affected by genes that determine the lowest node at which flowering can occur (control 6) (Murfet, 1977).

For a whole plant, the rate of vegetative development can be measured as the number of days per node formed at a given stage: days to reach a developmental stage/number of nodes at that developmental stage. Each addition of a node is a quantitative advance of the vegetative development. Further, each node provide one additional site for future flowers. The potential number of flowers, therefore, depends on the extent of vegetative development. Growth of initiated buds toward flower anthesis constitutes advancement of reproductive development, but it does not increase the number of buds or flowers. Therefore, the rate of development to flowering must be calculated (according to Summerfield and Roberts, 1988) as: 1/DTF. Summerfield and Roberts (1988) concluded that the time needed to reach a defined developmental stage is a consequence of the rate of progress toward this stage and not vice versa. On the contrary, calculation of the rate of both vegetative and reproductive development begins with the consequence of that rate.

In controlled environments, means of 18 to $26 \mathrm{C}$ caused a Ushaped curve of DTF for 15 of 16 bean genotypes (Muhammad, 1983). The exception was the highly photoperiod-sensitive 'Cargamanto', which either never flowered or had increased DTF with every increase of temperature. This apparent anomaly will be explained in the discussion. The 16 cultivars spanned the known range of germtypic sensitivities to photoperiod. Their diverse origins indicated adaptation to a wide range of temperatures. The U-shaped temperature response curve of the photoperiod-sensitive genotypes was altered strongly by daylength. Conversely, daylength minimally altered DTF of the insensitive genotypes. Also for them, shift of DTF from decreases with each higher temperature to increases was observed only at the highest temperatures tested. The optimum temperature for development to flowering is indicated by the fewest DTF on the U-shaped curve (Summerfield and Roberts, 1988; Wallace, 1985). Across factorial combinations of daylength and temperature, this optimum was lowered by increased sensitivity of the genotype to photoperiod and also by extension of the daylength.

The genotype $\times$ daylength $\times$ temperature interaction across the 16 genotypes (Muhammad, 1983) repeated a pattern reported (Wallace and Enriquez, 1980) in controlled environments for the photoperiod-insensitive genotype of the early maturing bean cultivar Redkloud compared against the late-maturing, photoperiod-sensitive 'Redkote'. The pattern will be summarized in the discussion.

In controlled environments, daylength and genotype for sensitivity to photoperiod have also been shown to alter the Ushaped temperature response curve of DTF in pea (Pisum sativum L.) (Berry and Aitken, 1979; Paton, 1968), several grain legumes (Ellis et al., 1988; Hadley et al., 1983; Roberts and Summerfield, 1987), barley (Hordeun vulgare L.) (Ellis et al., 1988), maize (Zea mays L.) (Aitken, 1980), and other crops as reviewed previously (Wallace, 1985). Early observations of the U-shaped response to temperature by Aitken (1974) were with field plantings at different elevations and latitudes for two grain legumes, two pasture legumes, four cereal crops, and two pasture grasses.

Objectives of our research were to: 1) determine if the Ushaped curve of DTF occurs for Phaseolus vulgaris in response to a range of mean temperatures in the field, 2) explain alterations of the U-shaped response to temperature by daylength and the genotype for sensitivity to photoperiod, 3) relate the Ushaped temperature response of DTF to the simultaneous alteration by this temperature of the rate of node development, 4) partition and quantify the genotype $\times$ daylength $\times$ temperature interaction effects statistically, 5) determine correlation of DTF with the number of nodes on shoots of the plant and with the other controls over DTF. Interaction effects on DTF among the six mentioned controls over DTF were considered.

\section{Materials and Methods}

Temperature experiment. Ten black-seeded Guatemala bean cultivars of indeterminate bush habit (type II) were grown in yield trials in Guatemala (Masaya and Wallace, 1984). In 1982 and again in 1983, these genotypes were planted in fields at five elevations. Within each year, all five plantings were on the same day of May. At 14 to $15^{\circ} \mathrm{N}$, daylength was $13.0 \mathrm{~h}$ in May, $13.3 \mathrm{~h}$ in late June, and $13.0 \mathrm{~h}$ in August. The elevations for 1982 were $2380,2200,1786,895$, and $478 \mathrm{~m}$. Respective means of all the daily average temperatures were 14.7, 15.7, $18.0,23.1$, and $25.4 \mathrm{C}$. The elevation corresponding to $15.7 \mathrm{C}$ was not replanted in 1983. Instead, the fifth site was at $50 \mathrm{~m}$, which had the highest (28.3C) mean temperature used in this study.

A randomized complete block with four replications was grown at each location. In each replicate, number of days from planting to first flower was recorded for five preselected plants of each genotype. Also recorded was number of nodes from the base of the main stem to the first flower. When the first flower was on a branch, node count continued onto that branch. The average for the five plants was used as the DTF and node to first flower (NTF) of each replicate.

Daylength-temperature experiment. In Colombia at 3 to $4^{\circ}$ $\mathrm{N}$ latitude, 68 bean genotypes were grown (Gniffke, 1985). They originated in many countries, represented adaptations to many daylengths and temperatures, and included the full range of growth habits. These cultivars, their growth habits, and their photoperiod sensitivities have been described previously (Gniffke, 1985). Incandescent lamps extended daylength of four replicates to $18.0 \mathrm{~h}$. Another four under natural $12.3 \mathrm{~h}$ daylength were $\approx 100 \mathrm{~m}$ distant. In late 1982 , the genotypes were planted at 2710,1850 , and $1001 \mathrm{~m}$ elevation. The plantings were repeated in early 1983. Seasonal temperatures varied slightly to give respective mean temperatures of 12.3 and $13.7 \mathrm{C}, 17.6$ and $19.0 \mathrm{C}$, and 23.5 and $23.7 \mathrm{C}$ for the 2 years. A plot was five plants of the genotype in a $1-\mathrm{m}$ row. DTF was statistically analyzed using the average DTF of the five plants representing each of the four replicates. Gniffke (1985) summarized the average DTF across all four replicates for each cultivar within both the 1982 and the 1983 planting. Data collection was terminated at 100 days after planting at the two lower (warmer) elevations. Collection ended after 150 and 170 days at the highest (coolest) elevation. A randomized complete block design was used in the field and for the statistical analysis. To reduce competitive effects by differential plant heights, the cultivars with bush habit and those with climbing habit were in a separate randomly positioned block within each replicate. Cultivars with climbing habit were supported with trellises. To avoid suggesting misleading effects because of the differing times to termination, failures to flower are positioned at a standardized 150 days for the graphically presented DTF of individual cultivars.

Sensitivity to photoperiod. The increases vs. decreases of DTF 
by daylength and by mean temperature were compared against photoperiod sensitivity ratings previously assigned for most of the cultivars by Centro Internacional Agricultura Tropical (CIAT) at its Palmira, Colombia. experiment station (Gniffke, 1985). The environment of Palmira and the procedures' used were those described herein for the 1001-m elevation of the daylengthtemperature experiment. The assigned photoperiod sensitivities indicated the following delays of DTF by extension of the natural 12-h daylength to $18 \mathrm{~h}$ : $1=$ less than 4 days delay; $2=$ 5 to 10 days; $3=11$ to 20 days; $4=21$ to 30 days; $6=$ more than 40 days; $8=$ failed to flower within 100 long days. If previously determined, this rating of sensitivity to photoperiod is presented in parentheses adjacent to the graphically shown genotypic response, or is presented with a specified symbol.

Plant habit. The effect of growth habit on DTF was considered by ranking the CIAT-designated habits (types I-A, I-C, II, HI, IV-A, and IV-B) into ranks from 1 to 6 , respectively. Type I is determinate bush, type II is indeterminate bush, and III and IV are indeterminate with progressively more nodes on the shoots and more tendency to climb. Thus, from ranks 1 to 6 , the vegetative structure of the plant habit includes progressively more nodes and branches (Gniffke, 1985; van Schoonhoven and Pastor-Corrales, 1987). The effect on DTF by this progressively larger vegetative development was ascertained using the correlation of ranks 1 to 6 with the cultivars mean DTF and sensitivities to photoperiod.

Statistical analysis. Analysis of variance (ANOVA) of both experiments had previously established that genotype, environment, and genotype $\times$ environment $(\mathrm{G} \times \mathrm{E})$ interaction all significantly controlled DTF (Gniffke, 1985; Masaya and Wallace, 1984). Further analysis was based on the AMMI model (Zobel et al., 1988). The computer program used was Matmodel version 2 (Gauch, 1990a), modified for use on a Macintosh SE30.

In this document, a treatment is considered to be one genotype in combination with one environment. The AMMI analysis partitions out three separate effects on the difference between a treatment mean and the grand mean. A mathematical description of the relationship between these effects is:

$$
\mathrm{Y}_{\mathrm{ger}}=\mu+\alpha_{\mathrm{g}}+\beta_{\mathrm{e}}+\sum_{\mathrm{n}=1}^{N} \lambda \gamma_{\mathrm{g}} \delta_{\mathrm{e}}+\epsilon_{\mathrm{r}} .
$$

From this model, the mean DTF of a treatment consists of: 1) the grand mean DTF of all the data $(\mu)$ plus 2$)$ the deviation from the grand mean DTF due to the genotype $(\alpha)$ plus 3 ) the deviation from the grand mean DTF due to the environment (B) plus 4 ) the effect on the deviation from the grand mean DTF due to the interaction of the genotype with the environment $(\gamma)$ multiplied by 5) the effect on the deviation due to the interaction of the environment with the genotype $(\delta)$ and finally the random error $(\in)$ due to replication. The first three and the last term are all strictly additive. The product of the interaction terms and a scaling term $(\lambda)$ is also additive. Both of the multiplicative effects (the interaction terms) have unit values and the scaling term is in DTF. Therefore, their product plus the three directly additive effects predicts (estimates) the mean DTF of the referenced genotype in the referenced environment (the treatment) across replications.

AMMI analysis uses ANOVA to quantify the grand mean plus the mean genotype-caused deviation from the grand mean DTF and the mean environment-caused deviation. In statistical terms, these are the main effect by the genotype and the main effect by the environment. To quantify the interaction effects on the deviation from the grand mean DTF of the treatment mean DTF, AMMI applies principal components analysis (PCA) to the total $\mathrm{G} \times \mathrm{E}$ interaction sum of squares (the residual from the ANOVA). The sum of squares was partitioned into successively smaller interaction-PCA components (IPCA axes 1, 2, 3, etc.). AMMI derives each component effect as an interaction score produced by multiplying the appropriate eigenvector $(\gamma$ or $\delta$ ) by the square root of the singular value $\left(\lambda^{0.5}\right)$. The successive axes were derived from the progressively smaller patterns of interaction-caused changes in DTF within the total $G$ $\times \mathrm{E}$ variance.

The number of axes considered to affect DTF significantly was determined by estimating the amount of the total sums of squares of all treatments that was due to random noise. This statistic was produced by multiplying the error mean square (MS) by the treatment degrees of freedom. Consideration of only significant axes was ensured by the discarded residual being at least as large as this product (Gauch, 1990b). There is one pair of multiplicative effects for each of the PCA axes that significantly affects a treatment mean.

Rather than presenting tables of means, the additive and multiplicative effects on the mean of each treatment are shown graphically for each statistically significant PCA axis. For each genotype and environment, its average DTF across all levels of the other is shown on the x-axis of a scatter plot, along with the grand mean. For each, its effect on the deviation from the grand mean through the $\mathrm{G} \times \mathrm{E}$ interaction is shown on theyaxis of the graph.

For genotypes that did not flower in all of the daylengthtemperature environments, an estimation maximization procedure was applied. It used AMMI to reiteratively calculate the partitioned contributions to the $\mathrm{G} \times \mathrm{E}$ effects derived across all 68 genotypes in factorial combination with all of the environments (see Gauch and Zobel, 1990). This procedure estimated the mean DTF for each nonflowering treatment. The DTF was estimated for $9.6 \%$ of the genotype-daylength-temperature combinations.

\section{Results}

$U$-shaped curve of DTF. In 1982, four of 10 genotypes ('Negro Pacoc', '80-13', 'Jutiapan', and '78-12') in the temperature experiment under the 13-h daylength expressed decreased DTF with each of the four temperature rises from 14.7 through $25.4 \mathrm{C}$ (Fig. 1). The smallest decreases were for the rise from 23.1 to 25.4C. The other six genotypes likewise had progressive decreases of DTF for the three rises from 14.7 through 23. 1C. However, the fourth rise to $25.4 \mathrm{C}$ gave a small increase in DTF (Fig. 1). All five 1982 sites were at elevations where beans were grown commercially.

No beans were planted in 1983 at the lowest mean temperature of 1982, but they were planted at a site with the highest mean temperature (28.3C) of this study. Beans were not grown commercially at this 50 -m elevation in the tropical lowlands. In 1983, all genotypes again expressed decreases in DTF with all rises from 15.7 to 23 . 1C. The small increase or decrease in DTF that each genotype had expressed in 1982 for the next rise to $25.4 \mathrm{C}$ was likewise generally repeated in 1983 . The final rise to $28.3 \mathrm{C}$ increased DTF for all 10 genotypes (Fig. 1). The largest increase in DTF caused by a temperature, which was above the optimum for flowering of the genotype, occurred for the most photoperiod-sensitive cultivar San Martin (Fig. 1).

Optimum temperature for flowering. The 68 genotypes of the daylength-temperature experiment were compared at 12.3 and 

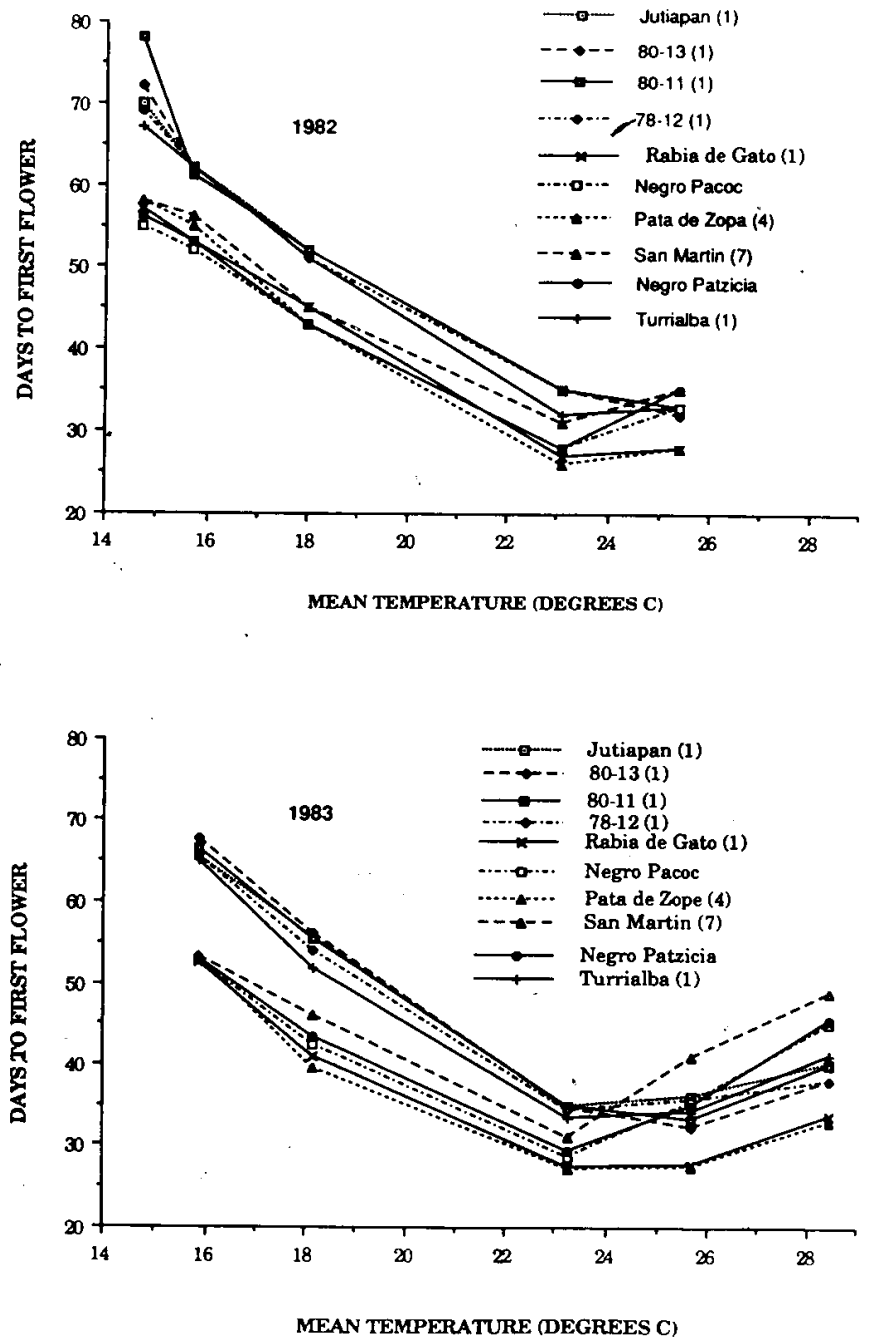

Fig. 1. Effects of 14.7 to $25.4 \mathrm{C}$ in 1982 and of 15.7 to $28.3 \mathrm{C}$ in 1983 on DTF of 10 indeterminate bush bean genotypes. (A rating for sensitivity to photoperiod is in parentheses adjacent to the cultivar name of each genotype; the sensitivities progressively increase from 1 to 7.$)$

13.7C, 17.6 and 19.0C, and 23.5 and 23.7C, with each temperature functioning in combination with 12- and 18-h daylengths. The three pairs of similar temperatures came from the 1982 and 1983 plantings at 2710-, 1850-, and 1001-m elevations, respectively. For each genotype, the small difference in temperate between the two plantings at the same elevation almost always caused the same increase or else decrease in DTF that was caused by the larger and spanning temperature difference between the adjacent elevations (Fig. 2). This verified the increase vs. decrease in DTF, which we interpreted as being caused by temperature.

Some genotypes with the highest photoperiod sensitivities (6 or 8) (Gniffke, 1985) expressed the U-shaped curve of DTF across the 12.3 to $23.7 \mathrm{C}$ range of temperatures, under both 12and 18-h daylengths. This feature is illustrated (Fig. 2) by 'ICA Viboral'. Across all 12 daylength-temperatures, 'ICA Viboral', 'Rojo 70', and other genotypes with sensitivities of 6 or 8 had the largest, and quantitatively most reversed, changes from decrease to increase of DTF. With sensitivities of 3, 4, and 5, intermediate quantitative reversals occurred. For these moderate sensitivities to photoperiod, decreases of DTF occurred with rises from the lowest to the intermediate temperatures, and in- creases of DTF occurred with rises from these intermediate to higher temperatures. Insensitive genotypes (with photoperiod sensitivity of 1) never changed from a decrease of DTF with each rise of the mean temperature.

A few genotypes with sensitivity of 8 , illustrated by 'ICA Viboral', had no delay of DTF by 18-h daylength at the lowest (12 to $14 \mathrm{C})$ temperatures. For them, on the contrary, the $18-\mathrm{h}$ daylength caused a large delay in DTF near $18 \mathrm{C}$ and yet a larger, indefinite delay near 24C. 'Rojo 70' was strongly delayed by $18 \mathrm{~h}$ at 12 to $14 \mathrm{C}$ and never flowered under $18 \mathrm{~h}$ with temperature above $18 \mathrm{C}$, but had a higher optimum temperature for flowering under a 12-h daylength than any other genotype with sensitivity of 8 .

Below 18C, DTF of the moderately photoperiod-sensitive genotypes (Fig. 2, 'ICA Linea 17', 'Redkote', and 'Porrillo Sintetico') was not delayed by an 18-h daylength. However, their DTF was moderately delayed by an. 18-h daylength at temperatures above $18 \mathrm{C}$. This delay at $18 \mathrm{~h}$ was extended further by temperatures near $23 \mathrm{C}$. In contrast, a 12-h daylengthcaused all of the same temperature rises from 12.3 to $23.7 \mathrm{C}$ to progressively decrease the DTF of these moderately sensitive genotypes.

The 18-h daylength, combined with progressively higher temperatures, synergistically delayed DTF for moderately sensitive genotypes (Fig. 2) and caused a synergistically, yet larger delay for the highly photoperiod-sensitive genotypes. Synergism was evidenced up to that combination of long daylength plus high temperature beyond which the genotype did not flower. In contrast, DTF of the photoperiod-insensitive genotypes (illustrated by 'Redkloud', 'Jamapa', and 'VRB 81047') decreased with every temperature rise from 12.3 to near $23.7 \mathrm{C}$, under both 12 and 18-h daylengths.

Genetically caused variability of the response to daylength and temperature was more evident among the most highly photoperiod-sensitive genotypes than among the moderately photoperiod-sensitive and insensitive genotypes. For instance, under an 18-h daylength, the optimum temperature for flowering of the highly photoperiod-sensitive 'Rojo 70' was near 18 , as occurred for all moderately sensitive genotypes. Further illustrating such genetic variability, $18 \mathrm{~h}$ of daylength lowered the optimum temperature for flowering of 'ICA Viboral' to near $14 \mathrm{C}$, and lowered the optimum for 'Mortino' to below $12 \mathrm{C}$.

Temperature vs. NTF. The number of nodes from the cotyledon to the first flower was measured at all five mean temperatures of the 1983 temperature experiment. Four increases of temperature from $15.7 \mathrm{C}$ times the 10 genotypes provided 40 observations of the effect of temperature on NTF. For 39 observations, the higher temperature increased the number of nodes between the cotyledon and the first flower (Fig. 3). The increases in NTF (Figs. 3 and 4) and in DTF (Fig. 1) by the above-optimum temperatures for flowering were largest for the most photoperiod-sensitive genotype.

Temperature vs. rate of node development. For the 1983 temperature experiment, the mean days to maturity of each cultivar was divided by the mean number of nodes on the plants at maturity to quantify the rate of vegetative development. The calculated mean days required to develop a node were $7.3,6.7$, $5.3,3.3$, and 2.1 at mean temperatures of 14.7, 15.7, 18.0, 23.3, and $25.7 \mathrm{C}$, respectively. The preflowering rate of vegetative development was measured in 1984 at the 18.0, 23.3, and $28.3 \mathrm{C}$ sites for three of the 10 cultivars plus a fourth, 'Quetzal'. All nodes on the plant were counted at flowering. The preflowering rate of vegetative development also increased 


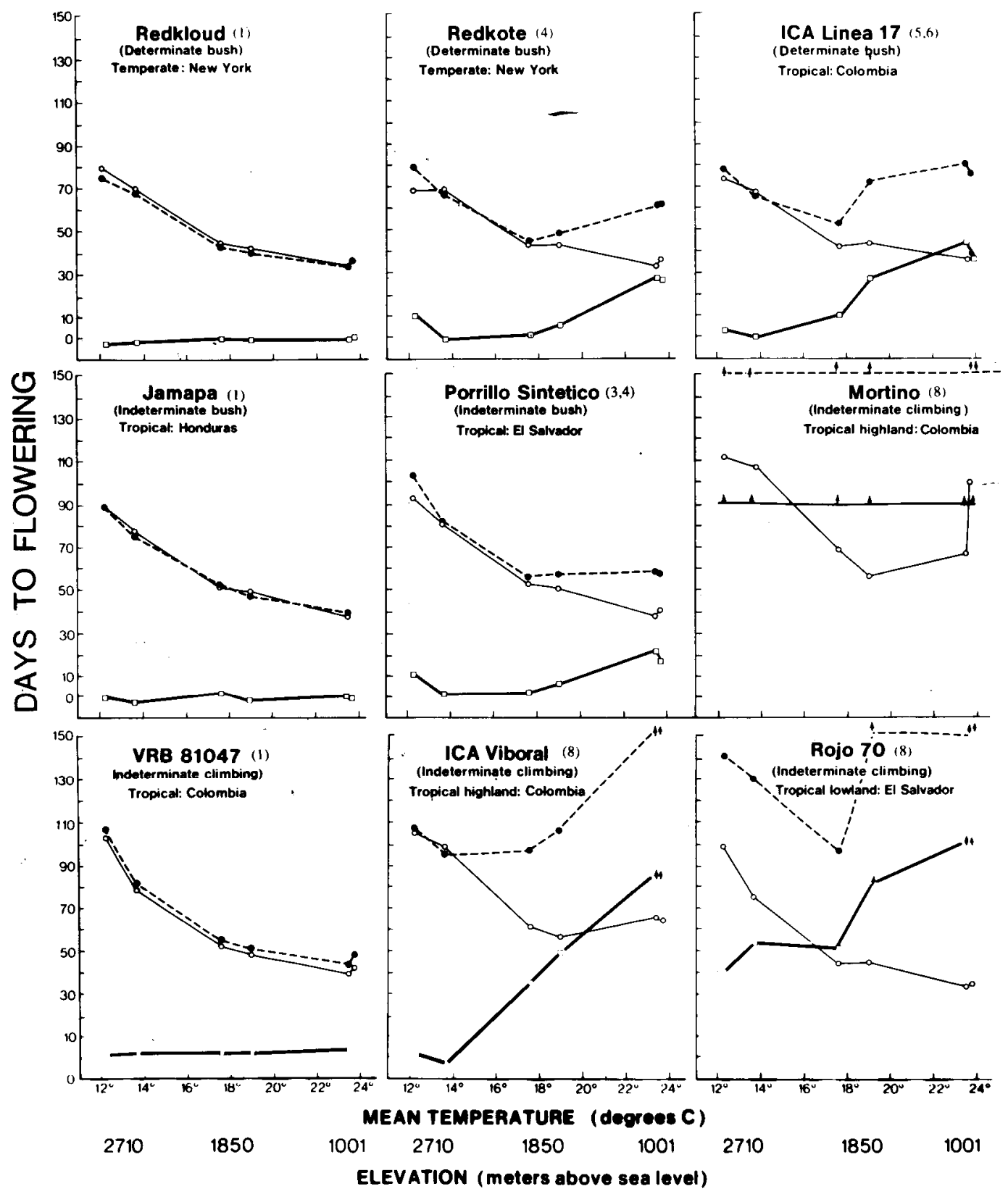

Fig. 2. Days to first flower and the delay of flowering caused by long daylength for nine diversely adapted bean genotypes grown under $12.3-$ and 18. O-h daylengths during two successive growing seasons at mean temperatures near 12 , 18 , and $24 \mathrm{C}$. (A rating for sensitivity to photoperiod is in parentheses adjacent to the cultivar name of each genotype; the sensitivity increases progressively from 1 to 8 .) DTF under 12.3-h natural daylength $(\mathrm{O}-\mathrm{O})$, DTF under incandescent-lamp-extended 18-h daylength ( $-\bullet$.), days delay by the long daylength ( $\square-\square$ ). Failure to flower during the observed 100,150, or 180 days is indicated by $\uparrow$.

with each temperature rise. Across the four cultivars (Fig. 4), the mean time required to develop a node was 6.1 days at $18 \mathrm{C}$, 3.0 days at $23.3 \mathrm{C}$, and 0.91 days at $28.3 \mathrm{C}$.

\section{Discussion}

Genotype $\times$ daylength $\times$ temperature interactions. The 1982 and 1983 plantings gave nearly identical DTF for each genotype, for each similar mean temperature at each elevation, and for the same 13.5-, 12-, or 18-h daylengths. From these repeated effects on DTF, the change of the U-shaped curve of DTF caused by each genotype, daylength, and temperature was determined. Interpretation was verified in that each small increase or decrease in mean temperature between the 1982 and 1983 plantings at the same elevation caused a smaller but qualitatively identical increase or decrease in DTF, as was caused by the larger change of temperature difference between the adjacent elevations. Changes of the U-shaped curve by genotype, daylength, and temperature in these field environments were qualitatively the same as observed previously in the two growth chamber studies mentioned in the introduction (Muhammad, 1983; Wallace and Enriquez, 1980).

The genotype $\times$ daylength $\times$ temperature interaction effects on DTF will be described by comparing the photoperiod-insensitive genotype 'Redkloud' with the moderately sensitive 'Redkote'. These contrasting genotypes have been compared in the factorial combinations of daylength and temperature of both of the previous controlled environment studies (Muhammad, 1983; Wallace and Enriquez, 1980), plus in the current daylength- 


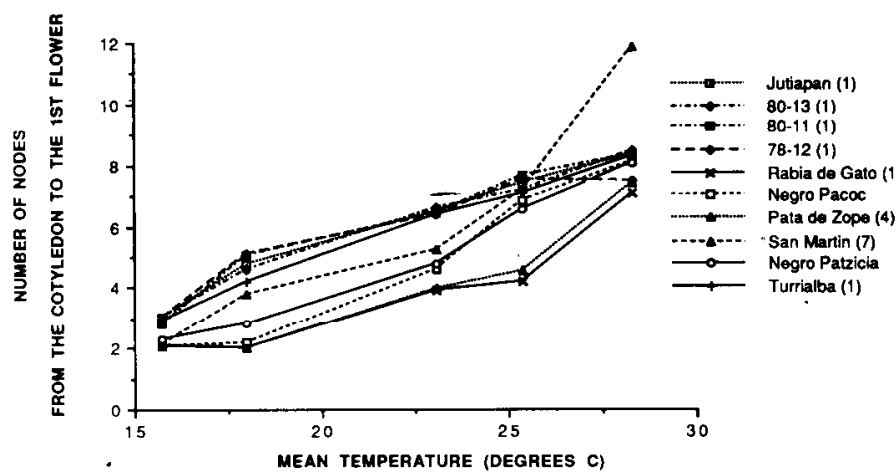

Fig. 3. Effects of 15.7 to $28.3 \mathrm{C}$ mean temperature on number of nodes between the cotyledon and the first flower for 10 bean genotypes with indeterminate bush plant habit.

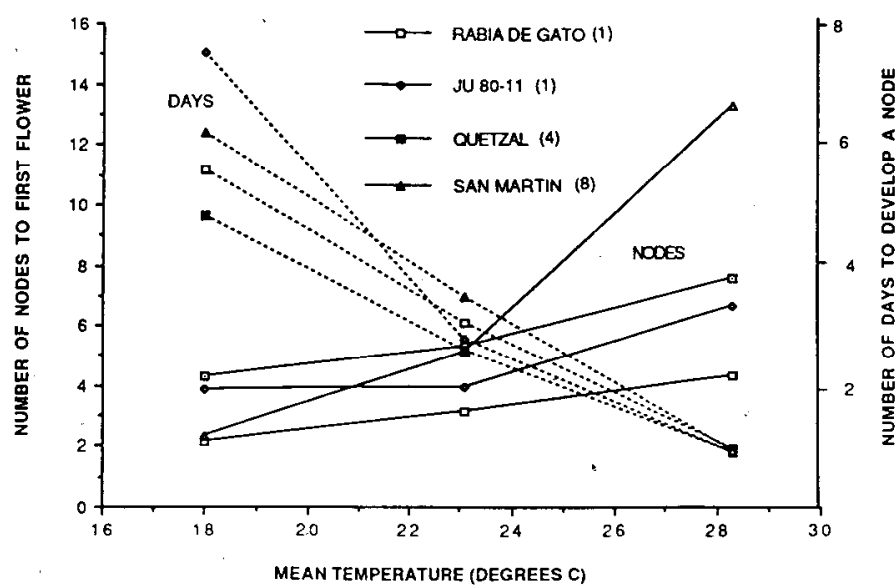

Fig. 4. DTF, days to develop a node, and NTF of four bean genotypes with indeterminate bush habit grown at mean temperatures of 18.0, 23.1 , and $28.3 \mathrm{C}$.

temperature factorial in tropical fields (Fig. 2). An optimum temperature for flowering is indicated by the smallest DTF on the U-shaped response to. temperature. In controlled-environment chambers at $21,24,27$, and $30 \mathrm{C}$, an optimum temperature for flowering $(27 \mathrm{C})$ was expressed only under the 12-h daylength (Wallace and Enriquez, 1980). Moreover, an optimum temperature, as evidenced by a U-shaped response of DTF to temperature, was expressed only by the moderately photoperiod-sensitive 'Redkote'. For the photoperiod-insensitive 'Redkloud', decreases of DTF were caused by each higher temperature in each of the 9,12,14, and 16-h daylengths. Likewise, under the 9-h daylength, which promoted rather than delayed flowering of the photoperiod-sensitive genotype, each successively higher mean temperature progressively decreased DTF of 'Redkote'. In contrast, a 14-h daylength, which delayed flowering of 'Redkote', also caused the three progressive rises of temperature to increase DTF progressively. The yet more-delaying 16$\mathrm{h}$ daylength resulted in further (synergistic) enlargement of the progressive increases of DTF by a higher temperature.

In the tropical fields used in this study, across means near 12,18 , and 24C, 'Redkote' expressed an optimum temperature for flowering at $18 \mathrm{C}$ in combination with the 18-h daylength (Fig. 2). Under a 12-h daylength, 'Redkote' expressed only decreases of DTF with these same rises of temperature. Similarly, 'Redkloud', as it had under all four daylengths within the controlled environments, expressed only decreases of DTF under both the 18- and 12-h daylengths in the field.
The lowering of the optimum temperature for flowering of the photoperiod-sensitive 'Redkote', from 27C under the 12-h daylength in the growth chamber to $18 \mathrm{C}$ under an 18 -h daylength in the field, illustrates a detail of the pattern of interaction that was discernible across all of the tested genotypes, daylengths, and temperatures. For the short-day, quantitative, photoperiod response of bean, this interaction pattern is as follows: The expressed optimum temperature for flowering is lowered by lengthening the daylength, and it is also lowered by an increased sensitivity to photoperiod of the genotype. This overall pattern of the three-factor interaction (genotype $\times$ daylength $\times$ temperature) effect on DTF could be discerned across the relatively low temperatures (12 to $23.7 \mathrm{C}$ ) of the daylength-temperature experiment because multiple levels of photoperiod sensitivity were compared across multiple levels of temperature in combination with the minimally required two levels of daylength.

The highest temperature $(23.7 \mathrm{C})$ of the daylength-temperature factorial in the field was near the 23.1 to $25.3 \mathrm{C}$ that was optimal for flowering in fields with $13 \mathrm{~h}$ of daylength. In the Guatemala fields with $13 \mathrm{~h}$ of daylength, the optimum temperature for flowering of 10 indeterminate bush (type II) cultivars could be determined only after they were also grown at the above-optimal 28.3C (Fig. 1). This high temperature strongly delayed the DTF of all 10 genotypes. This delay and its extension of the time the plants are exposed to high humidity and associated diseases has caused commercial bean production to be unprofitable in the lowland tropics. The 15 to $25 \mathrm{C}$ temperatures of the 1982 plantings were too low to reliably reveal the optimum temperature for flowering. Likewise, daylength may be too long, relative to the tested range of mean temperatures, to allow expression of the U-shaped response to temperature by a highly photoperiod-sensitive genotype. This was approached by 'ICA Viboral' under $18 \mathrm{~h}$ of daylength in the field (Fig. 2). It was fully shown by failure of 'Mortino' to flower at any mean temperature under $18 \mathrm{~h}$ of daylength (Fig. 2). All of the temperatures might also be too high, relative to the tested range of daylengths, to allow expression of the left side of the U-shaped curve of DTF. This was shown in the controlled environments (Muhammad, 1983). Fifteen other genotypes expressed the Ushaped curve of DTF, but 'Cargamanto' failed to flower under long daylength, and in short daylength, its DTF increased with each higher temperature.

It was not possible to conclude that a quantitatively identical DTF will result from an experimentally provided identical daylength-temperature in the growth chamber and field because different combinations of daylength and temperature were compared.

More than 80 bean genotypes have been compared across factorial combinations of daylength-temperature. Overall interpretation suggests that the DTF of all bean genotypes will follow a U-shaped curve in response to temperature, if a sufficient range of temperature and daylength is used. Temperatures that delay DTF need not be high enough to be generally detrimental to biological processes. A U-shaped temperature-response curve will be observable across temperatures compared under a single daylength if, by chance or previous knowledge, that daylength is near the optimum for flowering of the genotype when that daylength is functioning in combination with the intermediate levels of the tested range of temperatures.

The most highly photoperiod-sensitive cultivars, those with sensitivities of 6 and 8, such as 'ICA Viboral', 'Mortino', and 'Cargamento', have mostly originated at tropical highland lo- 
cations (Gniffke, 1985; White and Laing, 1989). The growing seasons are 6 to 9 months long and the mean temperatures are below 18C. All genotypes for which DTF was delayed by $18 \mathrm{~h}$ of daylength at 12 to $14 \mathrm{C}$ had these extreme sensitivities to photoperiod. Cultivars are usually selected for high yield as well as adaptation to a specific region. We suggest that selection for yield and adaptation has resulted in the associated extreme sensitivity to photoperiod. The extreme sensitivity could delay NTF and DTF even under a relatively short daylength and low mean temperature. This combination would extend the vegetative growth and development and facilitate high yield. Because of the same facilitation of yield, selection for high yield will simultaneously lead toward plant habits with more nodes. The genotypes with sensitivities of 6 and 8 will develop to flowering soon after emergence, if the daylength is shortened to 6 to $8 \mathrm{~h}$ (White and Izquierdo, 1989; White and Laing, 1989).

'Rojo 70' has a photoperiod sensitivity of 8 . It flowers and gives high yields in El Salvador, where it originated, but only during the season with short daylength $(\approx 11 \mathrm{~h})$ and low temperature. In the growth chamber and greenhouse, 'Rojo 70' never flowered above $\approx 26 \mathrm{C}$ or a daylength longer than $12 \mathrm{~h}$. 'Rojo 70' approaches the will flower vs. will never flower response to daylength (the qualitative rather than quantitative response) of the genotypes of the plant species preferred for basic studies of photoperiodism.

The described genotype (for sensitivity to photoperiod) $\times$ daylength interaction effect on the optimum temperature for flowering and on the attendant change of the U-shaped response of DTF to temperature were expressed bybean cultivars with the determinate bush habits (I-A and I-C), indeterminate bush habit (II), and by the progressively more vegetative and indeterminate climbing habits (III, IV-A, and IV-B).

Interpretation via AMMI analysis. To simplify presentation of the analysis, the 12 daylength-temperatures from two plantings $\times$ three elevations $\times$ two daylengths were reduced to a factorial of two daylengths $\times$ three elevations (six daylengthtemperatures). This was done by considering the mean DTF of each genotype across the four replicates at each elevation of the 1982 planting as one replication within a completely randomized experimental design. Each corresponding mean of the 1983 planting was considered as a second replication.

Main effects on DTF by the 68 genotypes and by the six environments were highly significant (Table 1 ). The $\mathrm{G} \times \mathrm{E}$ interaction effect was also highly significant. Genotypes accounted for $23 \%$ of the treatment sums of squares (Table 1), while environments (the combinations of daylength and temperature) accounted for $59 \%$ (Table 1). The $\mathrm{G} \times \mathrm{E}$ interaction sums of squares accounted for $17 \%$ of the variation among treatments. IPCA-1 and IPCA-2 plus the genotype and environment

Table 1. AMMI analysis of genotypic, environmental, and $\mathrm{G} \times \mathrm{E}$ interaction effects on the days to flowering of 68 bean genotypes grown within six daylength-temperatures.

\begin{tabular}{lrrrrr}
\hline \hline \multicolumn{1}{c}{ Source } & DF & \multicolumn{1}{c}{ SS } & \multicolumn{1}{c}{ MS } & \multicolumn{1}{c}{ F } & Probability \\
\hline Total & 654 & 430005 & 657.5 & & \\
Treatments & 407 & 416716 & 1023.9 & 22.0 & 0.0000000 \\
Genotypes & 67 & 97454 & 1454.5 & 9.8 & 0.0000000 \\
Environments & 5 & 246746 & 49349.3 & 1061.3 & 0.0000000 \\
$\quad$ G × E & 335 & 72516 & 216.5 & 4.7 & 0.0000000 \\
PCA axis 1 & 71 & 37899 & 533.8 & 11.5 & 0.0000000 \\
PCA axis 2 & 69 & 22129 & 320.7 & 6.9 & 0.0000000 \\
$\quad$ Residual & 195 & 12489 & 64.1 & 1.4 & \\
Error & 286 & 13289 & 46.5 & & \\
\hline
\end{tabular}

sums of squares accounted for $97 \%$ of the treatment sums of squares and comprised the optimum separation of pattern from noise within the treatment sums of squares.

Under $12 \mathrm{~h}$ of daylength, the average DTF across all 68 genotypes decreased from 85 to 51 to 43 days as the mean temperature rose from 13 to 18 to $24 \mathrm{C}$ (Fig. 5). Under $18 \mathrm{~h}$ of daylength, corresponding decreases were from 91 to 62 to 58 days. Averaged across all 68 genotypes (including imputed values of DTF for the combinations of genotype, daylength, and temperature for which flowering did not occur), $18 \mathrm{~h}$ of daylength delayed DTF 6 days at 13C, 11 days at 18C, and 15 days at $24 \mathrm{C}$. The longer daylength increased the average DTF across the 68 genotypes at all temperatures, while simultaneously increasing the positive effect on the deviation from the grand mean DTF through the $\mathrm{G} \times \mathrm{E}$ interaction (Fig. 5). The average delays of DTF caused by $18 \mathrm{~h}$ of daylength were positively correlated (0.98) with the mean temperature. The average DTF had a correlation coefficient $r$ of -0.90 with temperature under $18 \mathrm{~h}$ of daylength, but only -0.17 under $12 \mathrm{~h}$ (Table 2). With only two daylengths, the correlation with daylength could not be calculated.

The effect on the deviation from the grand mean DTF through the largest pattern of change of DTF due to $\mathrm{G} \times \mathrm{E}$ interaction was designated as IPCA-1. The second largest significant pattern was designated as IPCA-2.

In IPCA-1 of the daylength-temperature factorial of 68 genotypes, in tropical fields, all temperatures functioning under 12 $h$ of daylength caused negative deviation from the grand mean DTF (Figs. 5-7). At 13, 18, and 24C, temperatures had a correlation of 0.99 with their effect on the deviation under the 12 $\mathrm{h}$ daylength, but the correlation was reversed to -0.86 under $18 \mathrm{~h}$ of daylength. Extension to $18 \mathrm{~h}$ positively increased the effect on the deviation by 2.56 (days) $^{0.5}$ at $24 \mathrm{C}, 3.76$ (days) $^{0.5}$ at $18 \mathrm{C}$, and 13.1 (days) $)^{0.5}$ at $13 \mathrm{C}$. The effect on the deviation also became more positive as the photoperiod sensitivity of the genotype increased (Figs. 5-7). The effect on the deviation due to genotype ranged from -1.1 (days) ${ }^{0.5}$ to 5.1 (days) ${ }^{0.5}$, except for one outlying genotype with -7.0 (days) $)^{0.5}$. This range of 6.2 (days) ${ }^{0.5}$ across all but the outlying genotype is smaller than the 10.8 (days) $)^{0.5}$ range due to the effect of 13,18 , and $24 \mathrm{C}$ under $18 \mathrm{~h}$, but is much larger than the 0.9 (days) ${ }^{0.5}$ range caused by these temperatures under $12 \mathrm{~h}$ of daylength. The overall range through the $\mathrm{G} \times \mathrm{E}$ interaction caused by change from 12 - to 18 -h daylengths was 14.1 (days) $)^{0.5}$.

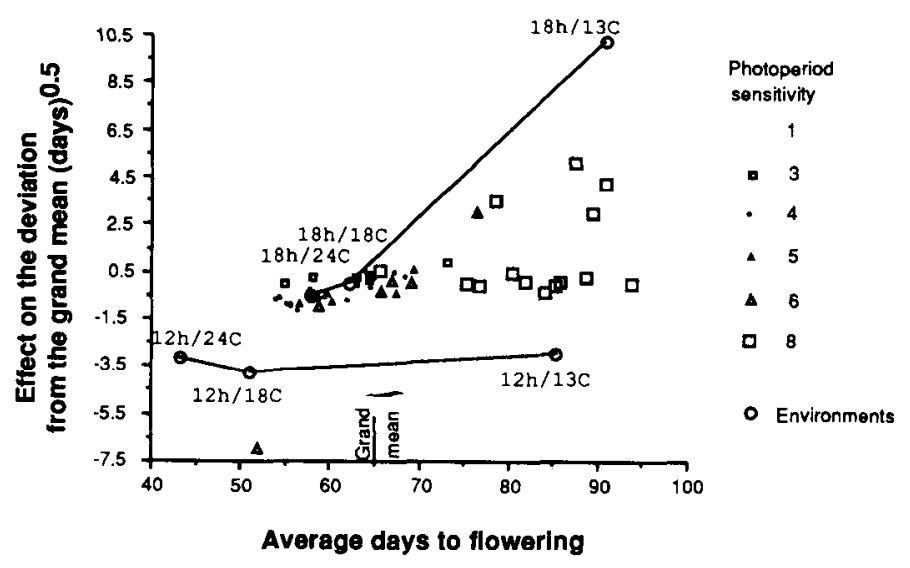

Fig. 5. The largest contribution (IPCA-1) to the deviations from the grand mean DTF through the $\mathrm{G} \times \mathrm{E}$ interaction for 68 genotypes and six daylength-temperatures plotted against the mean DTF of these genotypes and environments. 
Table 2. Correlations of mean DTF and of the $G \times E$ effects on deviation from the grand mean DTF with genotypic sensitivity to photoperiod, plant habit, and the mean temperature in combination with both 12- and 18-h daylengths.

\begin{tabular}{|c|c|c|c|c|c|c|c|}
\hline & \multirow{2}{*}{$\begin{array}{c}\text { Photoperiod } \\
\text { sensitivity }\end{array}$} & \multirow{2}{*}{$\begin{array}{c}\text { Vegetativeness } \\
\text { of habit }\end{array}$} & \multicolumn{2}{|c|}{ Temp } & \multirow[b]{2}{*}{ Axis 1} & \multirow[b]{2}{*}{ Axis 2} & \multirow[b]{2}{*}{ Axis 3} \\
\hline & & & $12 \mathrm{~h}$ & $18 \mathrm{~h}$ & & & \\
\hline & \multicolumn{7}{|c|}{ Across all 68 genotypes } \\
\hline Mean & 0.76 & 0.75 & -0.17 & -0.90 & \multirow[t]{5}{*}{0.24} & \multirow{5}{*}{$\begin{array}{r}0.03 \\
-0.01\end{array}$} & \multirow{5}{*}{$\begin{array}{l}0.58 \\
0.00 \\
0.00\end{array}$} \\
\hline Axis 1 & 0.30 & 0.41 & 0.99 & -0.86 & & & \\
\hline Axis 2 & 0.74 & 0.12 & -0.08 & 0.95 & & & \\
\hline Axis 3 & 0.27 & 0.34 & -0.92 & -0.42 & & & \\
\hline Axis 4 & NS & & & & & & \\
\hline & \multicolumn{7}{|c|}{ Across 36 genotypes that flowered in all daylength-temperatures } \\
\hline Mean & 0.43 & 0.51 & -0.94 & -0.86 & -0.78 & 0.52 & \\
\hline Axis 1 & 0.93 & -0.58 & 0.99 & 0.99 & & -0.94 & \\
\hline Axis 2 & -0.34 & -0.51 & 0.93 & 0.63 & & & \\
\hline Axis 3 & NS & & & & & & \\
\hline
\end{tabular}

${ }^{2}$ There were only two daylengths, so calculated correlations were meaningless.

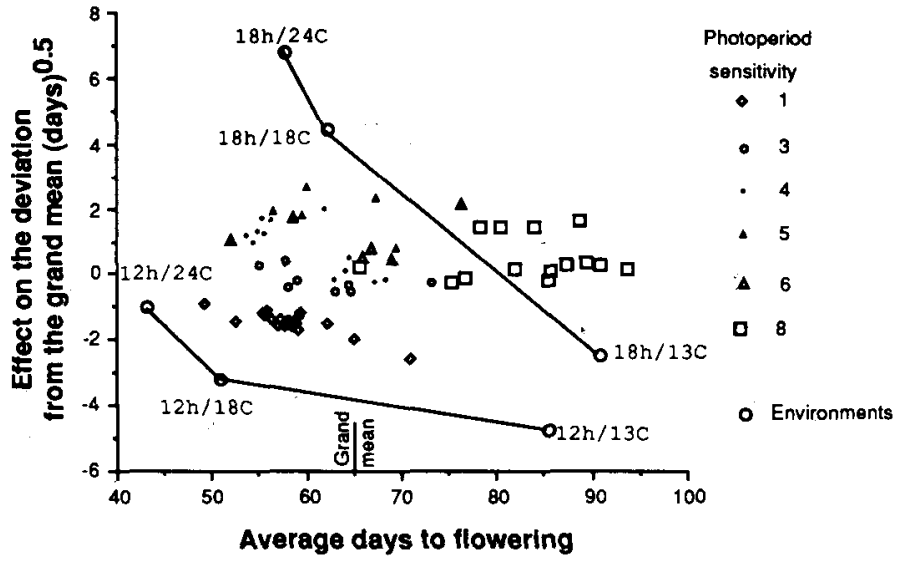

Fig. 6. The second largest contribution (IPCA-2) to the deviations from the grand mean DTF through the $\mathrm{G} \times \mathrm{E}$ interaction for68 genotypes and six daylength-temperatures plotted against the mean DTF of these genotypes and environments.

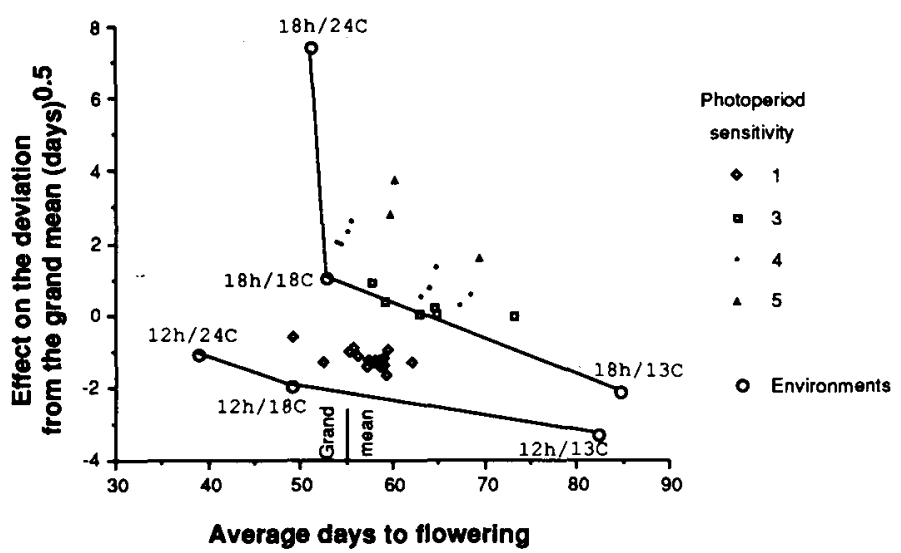

Fig. 7. The largest contribution (IPCA-1) tothedeviations from the grand mean DTF through the $\mathrm{G} \times \mathrm{E}$ interaction for 36 genotypes and six daylength-temperatures plotted against the mean DTF of these genotypes and environments.

Under $18 \mathrm{~h}$ of daylength, across all 68 genotypes, the change toward a more positive effect on the deviation from the grand mean caused by each lower temperature for IPCA-1 (Fig. 5) was opposite to the change toward more negative deviation caused by the same lower temperatures for IPCA-2 (Fig. 6). For
IPCA-1, correlation of effects on the deviation with temperature was -0.98 under $18 \mathrm{~h}$, compared to -0.12 under $12 \mathrm{~h}$. At both 18 and $12 \mathrm{~h}$ of daylength, all effects by IPCA-2 for the 68 genotypes (Fig. 6) were similar to the effects by IPCA-1 for the 36 genotypes that flowered in all environments (Fig. 7). This is explained as follows:

For IPCA-1, the most photoperiod-sensitive genotypes (6 and 8) caused the largest, most positive effect on the deviation and the largest average DTF (Fig. 5). Their effect on the deviation was largest because some of them were the only genotypes that were delayed in flowering by $18 \mathrm{~h}$ of daylength combined with the lowest (13C) mean temperature (Fig. 2). All of the genotypes with sensitivities of 6 and 8 had a second effect toward positive deviation from the grand mean. As the temperature was raised from 13 to 18 to $24 \mathrm{C}$, their flowering was delayed more than the less photoperiod-sensitive genotypes. None of them flowered under $18 \mathrm{~h}$ of daylength combined with 24C. Some never flowered under $12 \mathrm{~h}$ of daylength and 24C (Fig. 2).

As a third cause of deviation from the grand mean DTF, some of the most strongly photoperiod-sensitive genotypes failed to flower in all of the combinations of daylength and temperature (Figs. 2, 5, and 7), probably because they also have the most vegetative plant habits. Their type IV-A or IV-B habits required development of the most nodes. By definition, habit IV-B includes bearing of flowers and pods on the uppermost of its many nodes and branches (Gniffke, 1985; van Schoonhoven and Pastor-Corrales, 1987). The habits with the fewest nodes (I-A and I-C) on the shoots have a small DTF, and habit II, and especially III, with intermediate node number generally have intermediate DTF. Correlation was 0.75 between DTF and the rank for vegetativeness of the plant habit (Table 2). IPCA-1 divided the genotypes with the most vegetative habits, which also have the previously assigned largest photoperiod sensitivities of 6 or 8 , into one group with moderately high positive effect on the deviation by the genotype plus a second with the highest of all genotype-caused effects on the deviation (Fig. 5). This relationship may be explainable as follows:

Sensitivities of 8 had been assigned previously to bean lines that did not flower within 100 days when the 12-h daylength was combined with the $24 \mathrm{C}$ mean temperature. For some of these genotypes, failure to flower within 100 days may have been caused more by the extreme vegetativeness of their plant habit or by differences in rate of node development than by their sensitivity to photoperiod. Progressively more vegetative habit 
had a correlation of 0.75 with the average DTF of the genotype across all of the environments (Table 2). Sensitivity to photoperiod was similarly correlated (0.76) with this average DTF of the genotype.

The 14.1 (days) ${ }^{0.5}$ range of the effect on the deviation caused by daylength (Fig. 5) and the 10.8 (days) ${ }^{0.5}$ range caused by mean temperature were about twice the 6.2 (days) ${ }^{0.5}$ range caused by the genotypes. Therefore, enlargement of the effect on the deviation by increased sensitivity to photoperiod was not as readily observable within the IPCA- 1 graph for all 68 genotypes (Fig. 5) as it was within the graph for IPCA-2 (Fig. 6). Across the 36 genotypes that flowered in all environments, positive enlargement of the effect on the deviation by increased sensitivity to photoperiod was yet more easily seen for IPCA-1 of the $\mathrm{G} \times \mathrm{E}$ interaction (Fig. 7).

The graphic demonstrations of increase of the positive effect on the deviation by higher sensitivity to photoperiod are supported by progressively higher correlations of $0.30,0.74$, and 0.93 between the effects and sensitivities (Table 2). For the AMMI analysis across all 68 cultivars, the higher correlation for IPCA-2 than IPCA-1 appears to result because IPCA-1 included the large effect on the deviation by the extreme vegetativeness (climbing habit) associated with most of the cultivars having the sensitivities 6 and 8. IPCA-1 removed and separated these effects from IPCA-2, the second largest effect on the deviation through $\mathrm{G} \times \mathrm{E}$ interaction.

We concluded that similarity of the IPCA-2 axis for all 68 genotypes with the IPCA-1 axis for the 36 genotypes that flowered in all daylength-temperatures resulted from both axes being due to the changes of DTF caused by interaction of the daylength-temperatures with the genotypes having photoperiod sensitivities of 1 to 5 .

Correlation between sensitivity to photoperiod and a progressively more vegetative plant habit was 0.43 (Table 2). This positive correlation agrees with our suggestion above that selection for yield and climbing habit in the long, cool growing season with short daylength of the highland tropics will result in correlated enlargement of both sensitivity to photoperiod and the number of nodes and branches of the plant habit. In contrast, selection for yield within the shorter, warmer, and long-daylength environments of growing seasons in the temperate zone will tend to decrease both the level of sensitivity to photoperiod and the number of nodes and branches on the plant. This tendency will be furthered by high yield under mechanized production systems.

The full range of photoperiod sensitivities occurred with the habit with the fewest nodes (I-A) and with the next to most vegetative habit (IV-A) (Figs. 2, 5, and 6). This relationship indicates that the positive correlation between photoperiod sensitivity and vegetativeness of the plant habit is due to selection for adaptation and yield; it is not caused by an unbreakable genetic linkage.

The temperature experiment involved five mean temperatures in factorial combination with 10 genotypes and one $(13 \mathrm{~h})$ daylength., An increase in temperature from the lowest (near 16C) to higher ones slowly changed the effect on the deviation from the grand mean through the $\mathrm{G} \times \mathrm{E}$ interaction toward becoming more positive, while decreasing the average DTF. Both effects by temperature continued up to the optimum for flowering, near 23 to $24 \mathrm{C}$ (compare Figs. 1 and 2 with Fig. 8). The aboveoptimum temperatures of 25 and $28 \mathrm{C}$ caused much larger and progressively more positive effects on the deviation from the grand mean and simultaneously increased rather than decreased

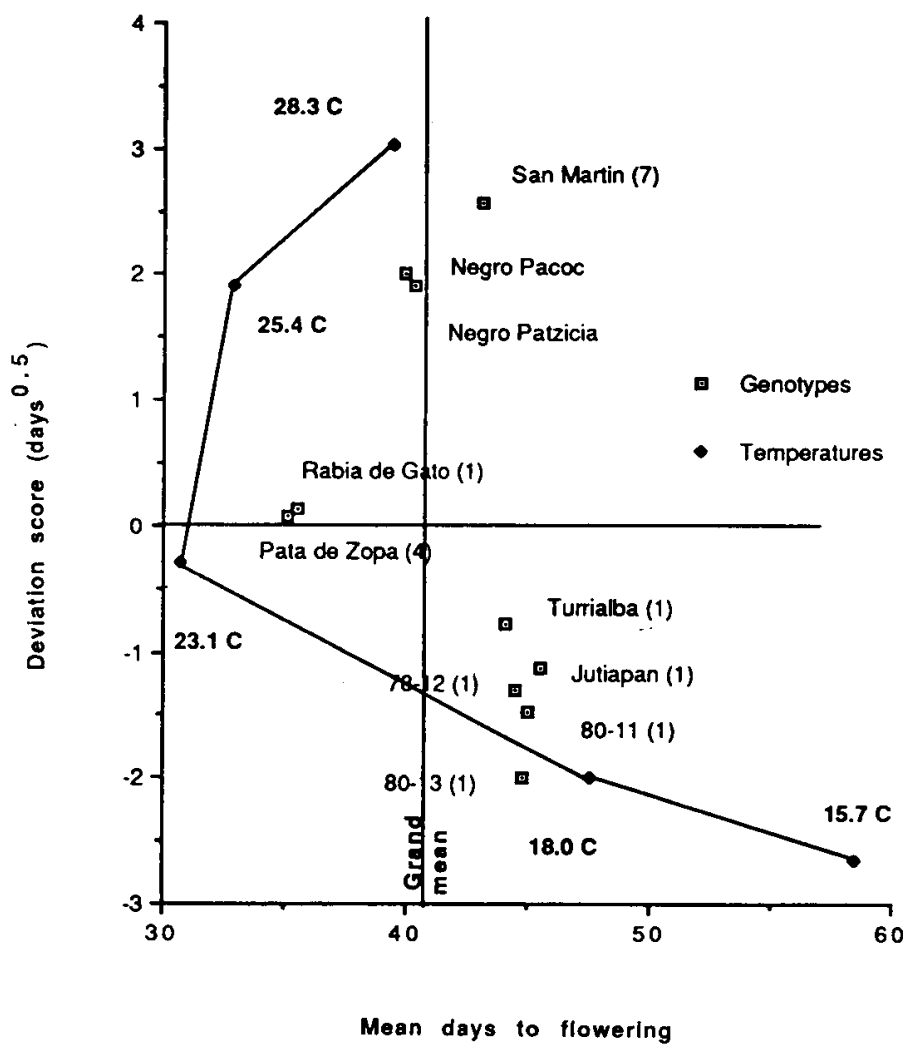

Fig. 8. The largest contribution (IPCA-1) to the deviations from the grand mean DTF through the $\mathrm{G} \times \mathrm{E}$ interaction for 10 genotypes and five mean temperatures plotted against the mean DTF of these genotypes and environments.

the average DTF. Higher sensitivity to photoperiod also enlarged both the positive effect on the deviation through the $G$ $\times \mathrm{E}$ interaction and the average DTF of the genotype across all environments (Fig. 8). These effects support our conclusion that temperatures above the optimum for flowering of the genotype interact with long daylength; they synergistically enhance delay of flowering through the activity of genes that control the response to photoperiod. Genotypes with insensitivity to photoperiod will express a relatively small photoperiod-gene-caused delay of flowering (Figs. 1, 2, and 8), if the combination of extended daylength plus higher temperature becomes sufficiently large.

\section{Literature Cited}

Aitken, Y. 1974. Flowering time, climate and genotype. The adaptation of agricultural species to climate through flowering responses. Melbourne Univ. Press, Australia.

Aitken, Y. 1980. The early maturing character in maize (Zea maize L.) in relation to temperature and photoperiod. Z. Acker-und Pflanzenbau 149:89-106.

Bernier, G., J.M. Kinet, and R.M. Sachs. 1981. The physiology of flowering. vol. 1. The initiation of flowers. vol. 2. Transition to reproductive growth. CRC Press, Boca Raton, Fla.

Berry, G.J. and Y. Aitken. 1979. Effect of photoperiod and temperature on flowering in pea (Pisun sativum L.). Austral. J. Plant Physiol. 6:573-587.

Craufurd, P.Q. and F.R. Bidinger. 1988. Effect of the duration of the vegetative phase on shoot growth, development and yield in pearl millet (Pennisetum americanum (L.) Leeke). J. Expt. Bet. 39:124139.

Dormling, I., A. Gustafsson, and G. Ekman. 1975. Growth disorders 
and phenotypic variability in phytotron-culivated barley. Hereditas 79:255-272.

Ellis, R.H., E.H. Roberts, R.J. Summerfield, and J.P. Cooper. 1988. Environmental control of flowering in barley (Hordum vulgare L.). II. Rate of development as a function of temperature and photoperiod and its modification by low-temperature vernalization. Ann. Bet. 62:145-158.

Evans, A. 1973. Comments on: Plant architecture and physiological efficiency in the field bean, p. 279-286. In: Potentials of field beans and other food legumes in Latin America. Ser. Seminars 2E. Centro International de Agricultural Tropical, Cali, Colombia.

Gauch, H.G. 1990a. Matmodel version 2.0: AMMI and related analyses for two-way data matrices. Microcomputer Power, Ithaca, N.Y

Gauch, H.G. 1990b. Full and reduced models for yield trials. Theor. Applied Genet. 80:153-160.

Gauch, H.G. and R.W. Zobel. 1990. Imputing missing yield trial data. Theor. Applied Genet. 79:753-761.

Gniffke, P.A. 1985: Studies of phonological variation in the common bean (Phaseolus vulgaris L.) as modulated by mean temperature and photoperiod. PhD Diss., Cornell Univ., Ithaca, N.Y.

Hadley, P., R.J. Summerfield, and E.H. Roberts. 1983. Effects of temperature and photoperiod on reproductive development of selected grain legumes, p. 19-41. In: D.R. Davies and D.G. Jones (eds.). Temperate legumes: The physiological, genetics and modulation. Pitmans, London.

Kinet, J. M., R.M. Sachs, and G. Bemier. 1985. The physiology of flowering. vol. 3. Development of flowers. CRC Press, Boca Raton, Fla.

Lamoreaux, R. J., W.R. Chancy, and K.M. Brown. 1978. The plastochron index: A review after two decades of use. Amer. J. Bet. 65:586-593.

Masaya, P.N. and D.H. Wallace. 1984. Photoperiod x temperature $\mathrm{x}$ genotype effects on days to flowering of bean (Phaseolus vulgaris L.). The effect of elevation (temperature) on number of days to and node of flowering in beans. Bean Improv. Coop. Annu. Rpt. 27:199202.

Muhammad, A.F.H. 1983. The effects of temperature and daylength on days to flower and maturity in dry beans (Phaseolus vulgaris L.). PhD Diss., Cornell Univ., Ithaca, N.Y.

Murfet, I.C. 1977. Environmental interaction and the genetics of flowering. Annu. Rev. Plant Physiol. 28:253-278.

Paton, D.M. 1968. Photoperiodic and temperature control of flower initiation in the late pea cultivar Greenfeast. Austral. J. Biol. Sci. 21:609-617.

Roberts, E.H. and R.J. Summerfield. 1987. Measurement and prediction of flowering in annual crops, p. 17-50. In: J.G. Atherton (cd.). Manipulation of flowering. Proc. 45th Easter School, Faculty of Agr. Sci., Univ. of Nottingham, U.K.

Summerfield, R.J. and E.H. Roberts. 1988. Photo-thermal regulation of flowering in pea, lentil, faba bean and chickpea, p. 911-922. In: R.J. Summer-field (cd.). World crops: Cool season food legumes. Kluwer Academic Publishers, Hingham, Mass.

Tollenaar, M. and R.B. Hunter. 1983. A photoperiod and temperature sensitive period for leaf number of maize. Crop Sci. 23:457-460.

van Schoonhoven, A. and M.A. Pastor-Corrales. 1987. Standard system for the evaluation of bean germplasm. (Centro Intemacional de Agricultural Tropical, Cali, Colombia.

Vince-Prue, D. 1975. Photoperiodism in plants. McGraw Hill, New York.

Vince-Prue, D., B. Thomas, and K.E. Cockshull. (eds.). 1984. Light and the flowering process. Academic, New York.

Wallace, D.H. 1985. Physiological genetics of plant maturity, adaptation, and yield. Plant Breeding Rev. 3:21-167.

Wallace, D.H. and G.A. Enriquez. 1980. Daylength and temperature effects on days to flowering of early and late maturing beans (Phaseolus vulgaris L.). J. Amer. Soc. Hort. Sci. 105:583-591.

White, J.W. and J. Izquierdo. 1989. Dry bean: Physiology of yield potential and stress tolerance. Centro International de Agricultural Tropical, Cali, Colombia.

White, J.W. and D.R. Laing. 1989. Photoperiod response of flowering in diverse genotypes of common bean (Phaseolus vulgaris). Field Crops Res. 22:113-128.

Zobel, R. W., M.J. Wright, and H. Gauch. 1988. Statistical analysis of a yield trial. Agron. J. 80:388-393. 